\title{
Effects of aging and gender on micro-rheology of blood in 3 to 18 months old male and female Wistar (Crl:WI) rats
}

Viktoria Somogyi, Katalin Peto, Adam Deak, Bence Tanczos and Norbert Nemeth*

Received 4 November 2017

Accepted 8 March 2018

\section{Abstract.}

BACKGROUND: Age- and gender-related alterations of hemorheological parameters have not been completely elucidated to date. Experiments on older animals may give valuable information on this issue. However, the majority of rheological studies have been performed in young rodents.

OBJECTIVE: We aimed to investigate the influence of aging and gender on hemorheological parameters in rats.

METHODS: Coeval male $(n=10)$ and female $(n=10)$ Wistar $(\mathrm{Crl}: \mathrm{WI})$ rats were followed-up over 15 months. Blood samples were obtained from the lateral tail vein at $3,4,5,9,12,15$ and 18 months of age. Hematological parameters, red blood cell deformability (elongation under shear), osmotic gradient deformability and erythrocyte aggregation were tested. Body weight and the estrus cycle (in females) were also examined.

RESULTS: Erythrocyte aggregation showed age- and gender-related variations. Red blood cell deformability was greater in females and gradually decreased over the 15-month period in both genders. Erythrocyte aggregation was greater in male rats at most ages, but did not show consistent changes with age.

CONCLUSIONS: The micro-rheological parameters showed age-related alterations with gender differences. The effect of the estrous cycle cannot be excluded in female rats. The results provide reference data for studies of aging in rats and of the mechanism related to age and gender differences in hemorheology.

Keywords: Hemorheology, red blood cell deformability, red blood cell aggregation, gender differences, aging, rat

\section{Introduction}

Aging is a complicated and multi-factorial process, that involves complex processes affecting the cardiovascular system [1-4]. Numerous studies have reported that this physiological process is associated with changes in hemorheological parameters, including whole blood and plasma viscosity, platelet aggregation, and erythrocyte aggregation and deformability [5-13]. Besides the physiological changes during aging, the increased risk of morbidity and mortality in cardiovascular disorders and cancer, emphasize the importance of gerontological research.

\footnotetext{
*Address for correspondence: Norbert Nemeth MD, PhD, DSc, Department of Operative Techniques and Surgical Research, Institute of Surgery, Faculty of Medicine, University of Debrecen, H-4032 Debrecen, Nagyerdei krt. 98., Hungary. Tel.: +3652-416-915; Fax: +36-52-416-915; E-mail: nemeth@med.unideb.hu.
} 
During in vivo aging or storage, erythrocytes lose water, 2,3-bisphosphoglyceric acid, ATP, proteins, hemoglobin and vesicles. The result is volume decrease, alterations in surface charge and increasing density [14-16]. The progressive loss of cell area and cell dehydration is a characteristic feature of red cell aging [17] that happens continuously with red blood cells in the circulation, during their life-span of about 120 days. But with aging of the body, the rate of this process and the cellular properties affected may differ, as several hemorheological studies suggest [6,10-13].

In experimental medicine there is a lack of laboratory animal studies using modern micro-rheological instruments [18-20]. Experiments conducted on older animals can provide useful information for many age-related issues in human diseases [21-24]. However, the majority of rheological studies involve dominantly young, 3-4 months old animals, and rarely older, e.g. 6-month rodents, age in rats correlates only to about 18 years in human [25].

In an earlier study, we have investigated the gender differences of hemorheological parameters in healthy young laboratory animals [26]. In the current study we aimed to investigate the age- and gender differences in the hemorheological parameters (extended micro-rheological investigation panel) over a 15-month follow-up period in rats. The goal was to provide reference data source for further studies of ageing in animal models.

\section{Materials and methods}

\subsection{Experimental animals and blood sampling protocol}

The experiments were approved and registered by the University of Debrecen Committee of Animal Welfare (permission Nr.: 19/2011. UDCAW), in accordance with national (Hungarian Animal Protection Act, Law XVIII/1998) and EU regulations (Directive 2010/63/EU). Coeval male $(n=10)$ and female $(n=10)$ Wistar (Crl:WI) rats (Toxi-Coop Ltd., Hungary) were followed-up for 15 months. The animals were kept in standard cages in groups of two, with natural light-cycles, and were fed with commercial rodent chow (Bábolna rodent-specific CRLT/N). The temperature during the follow-up period was maintained at about $20-22^{\circ} \mathrm{C}$. Blood samples were obtained by puncturing the lateral tail vein (each time $\sim 0.5 \mathrm{ml}$, anticoagulant: K3-EDTA) at the age of 3 months (base value, tested in March), and later when the animals were $4,5,9,12,15$ and 18 months old.

The phase of the estrus cycle was determined by vaginal swab smear technique. The samples were taken during the morning hours between 7-9 am. After that, we let the smear samples to air-dry for overnight on the slides. The staining was a slightly modified Giemsa-staining protocol. The samples were fixed with absolute methanol for 30 seconds. The effective staining commenced after the fixation of the samples. We used stock Giemsa-stain solution (J.T. Bakers' histology/cytology Giemsa 3856.1000) on the samples for 1 minute, than rinsed the slides in distilled water until all the residual stain was washed off. The stained samples were air-dried for a night in a clean, dustless container and then observed under light microscope. The following vaginal cytology classification was used: proestrus-nucleated epithelial cells, estrus-cornified squamous epithelial cells, metestrus-clustered cornified squamous epithelial cells and polynucleated leukocytes and diestrus-circular leukocytes [27].

\subsection{Laboratory methods}

A semi-automated microcell counter (Sysmex F-800, TOA Medical Electronics Co., Ltd., Japan) was used to determine the hematological parameters. The device uses aperture-impedance principle to calculate the number of red blood cells, white blood cells and platelets. The concentration of hemoglobin 
was measured by photometry. For a single measurement $70 \mu \mathrm{l}$ blood sample was needed. Red blood cell count $\left(\mathrm{RBC}\left[10^{6} / \mu \mathrm{l}\right]\right)$, white blood cell count $\left(\mathrm{WBC}\left[\times 10^{3} / \mu \mathrm{l}\right]\right)$, monocyte + granulocyte $\%(\mathrm{Mo}+\mathrm{Gr} \%$ $[\%])$, hemoglobin concentration $(\mathrm{Hgb}[\mathrm{g} / \mathrm{dl}])$, hematocrit $(\mathrm{Hct}[\%])$, platelet count (Plt $\left[\times 10^{3} / \mu \mathrm{l}\right]$ ), mean corpuscular volume (MCV [f]]), mean corpuscular hemoglobin ( $\mathrm{MCH}[\mathrm{pg}]$ ) and mean corpuscular hemoglobin concentration (MCHC [g/dl]) are presented in this paper.

A light-transmittance method was used for determining red blood cell aggregation with the Myrenne MA-1 erythrocyte aggregometer (Myrenne GmbH, Germany) (Schmid-Schönbein et al., [28]). At 5 or 10 seconds after disaggregation at high shear rate, the aggregation index values $\mathrm{M}$ (at shear rate of $0 \mathrm{~s}^{-1}$ ) and M1 (at shear rate of $3 \mathrm{~s}^{-1}$ ) were calculated. The indices (M $5 \mathrm{~s}, \mathrm{M} 15 \mathrm{~s}, \mathrm{M} 10 \mathrm{~s}, \mathrm{M} 110 \mathrm{~s}$ ) increase with the enhanced red blood cell aggregation [18-20,28].

The deformability of red blood cells was determined using a LoRRca MaxSis Osmoscan rotational ektacytometer (Mechatronics BV, The Netherlands). The dimensionless elongation index (EI = $(\mathrm{L}-\mathrm{W}) /(\mathrm{L}+\mathrm{W}))$ of red blood cells was tested as a function of shear stress (SS [Pa]) $[18,19]$. Polyvinylpyrrolidone (PVP) - phosphate buffered saline (PBS) solution was used as high-viscosity suspending media (PVP: $360 \mathrm{kDa}$, Sigma-Aldrich Co. USA; PVP-PBS solution viscosity $=23.7-35.9$ $\mathrm{mPas}$, osmolality $=296-319 \mathrm{mOsmol} / \mathrm{kg}, \mathrm{pH}=7.0-7.2$ ) and all measurements were performed at $37^{\circ} \mathrm{C}$. We compared EI-SS curves with Lineweaver-Burk analysis, and determined the maximal elongation index $\left(\mathrm{EI}_{\max }\right)$, the shear stress value at half $\mathrm{EI}_{\max }\left(\mathrm{SS}_{1 / 2}[\mathrm{~Pa}]\right)$ and their ratio [29].

During the osmotic gradient ektacytometry (osmoscan) test, the elongation index values were determined at a constant shear stress value (30 Pa), while the osmolality was adjusted $(0-500 \mathrm{mOsmol} / \mathrm{kg})$ [18]. $250 \mu \mathrm{l}$ of blood was gently mixed in $5 \mathrm{~mL}$ PVP solution for the osmoscan test. The parameters given by the device were: minimal elongation index values measured at low-osmotic environment (EI min), maximal elongation index values (maximal EI max at the constant shear stress (not equal to $\mathrm{EI}_{\max }$ ), the osmolality values at which these minimum and maximal values were obtained ( $\mathrm{O}$ min and $\mathrm{O}$ max), the half-maximal elongation index in the hypertonic arm (EI hyper) and the corresponding osmolality at which it occurs (O hyper), and area under the individual elongation index-osmolality curves (AUC). The following were calculated based on those parameters: difference between maximal and minimal EI values $(\Delta \mathrm{EI})$, the difference between osmolality values at maximal and minimal $\mathrm{EI}(\Delta \mathrm{O})$, and their ratio [30].

\subsection{Statistical analysis}

Data are presented as mean values \pm standard deviations (S.D.). Differences within the groups (agerelated changes) were analysed by one-way ANOVA followed by post-hoc Bonferroni or Dunn where appropriate. For inter-group comparison (males versus females) $t$-test or Mann-Whitney rank sum test were used, depending on the normality of data distribution. A $p$ value of $<0.05$ was considered as statistically significant. Statistical analysis was made using SigmaStat (Systat Software Inc., San Jose, California, USA) software.

\section{Results}

\subsection{Bodyweight changes and estrous cycle}

During the 15 months of the study there was a significant increase in the body weight of the animals (Fig. 1). There was also a significant difference between the weights of male and female rats from the 

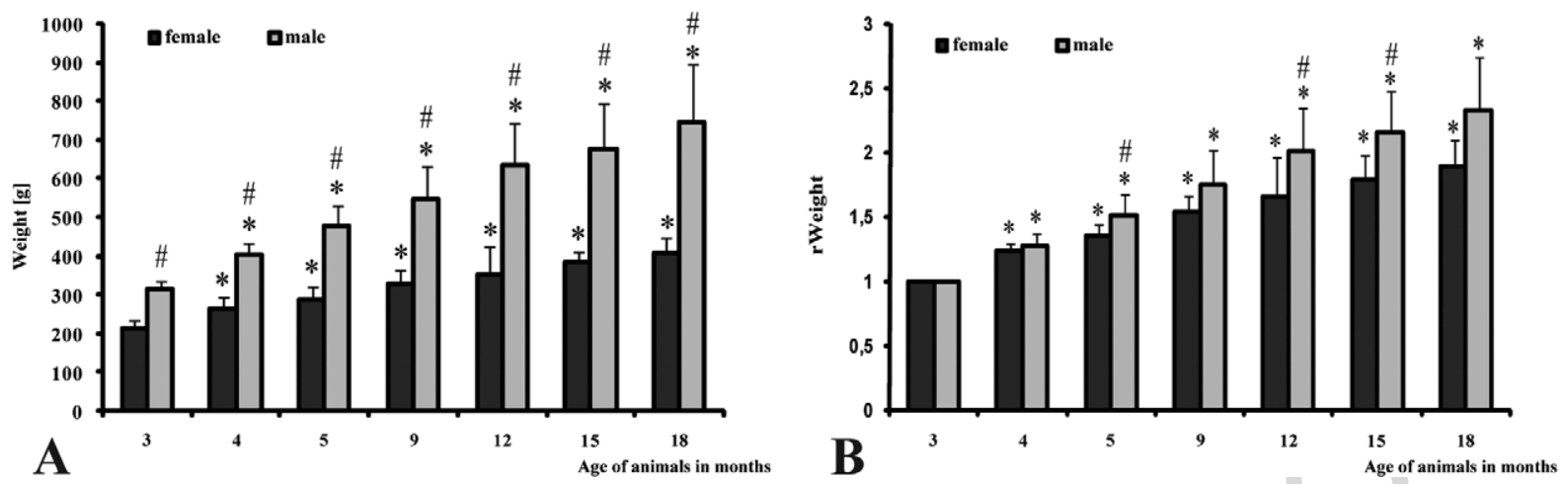

Fig. 1. Effects of age and gender on body weight of rats. Absolute (A) and relative (B) bodyweight changes of coeval male and female Crl:WI rats during the follow-up period at the ages of 3, 4, 5, 9, 12, 15 and 18 months. Data are means \pm S.D., ${ }^{*} p<0.05$ vs. 3 -month old, ${ }^{\#} p<0.05$ vs. female.

Table 1

Distribution of estrus cycle phases in coeval Crl:WI female rats. At ages of 3, 4, 5, 9, 12, 15 and 18 months, the percentage of female rats in each phase was calculated, based on the dominant microscopic picture of the vaginal smears [27]

\begin{tabular}{lcccccrc}
\hline Age (month) & 3 & 4 & 5 & 9 & 12 & $15^{*}$ & $18^{*}$ \\
\hline Pro-estrus & $40 \%$ & & & & $100 \%$ & $12.5 \%$ & $100 \%$ \\
Estrus & $60 \%$ & & $20 \%$ & & & $75 \%$ & \\
Metestrus & & & $80 \%$ & $100 \%$ & & $12.5 \%$ & \\
Diestrus & & $100 \%$ & & & &
\end{tabular}

${ }^{*}$ Number of evaluable smears $=8$.

second month of the observation. The female's average weight increased by $90 \%$, the male's by $133 \%$ by the end of the follow-up study, when the animals reached the age of 18 months.

Table 1 shows the changes in the estrous cycle of the female rats.

\subsection{Hematological parameters}

Figure 2 presents data for variation in the white blood cell count, monocyte-granulocyte ratio, red blood cell count and platelet count. Other hematological parameters are presented in Table 2. The white blood cell count declined over the first 9 months in females and was constant thereafter. In males it declined between 5 to 9 months and slightly increased afterwards. Consistently higher white blood cell counts were measured in the male rats. Monocyte+Granulocyte percentage gradually increased till the age of about 12-months in female and male rats. Throughout the whole follow-up period, the red blood cell count was higher in the male specimens, and increased between the 12th and 18th months. Platelet count was significantly higher in male rats compared to females in their 5th, 15th and 18th months only.

Hemoglobin ( $\mathrm{Hgb}$ ) and hematocrit (Hct) values tended to be higher in male rats (Table 2). Hgb was significantly higher in male than in female rats at 3, 4, 5, 9 and 15 months of age, and Hct higher at 5,9 and 15 months. By 15-18 months, Hgb and Hct tended to be higher than at 3 months.

Mean corpuscular volume (MCV [fl]) did not show consistent gender differences but was significantly higher in females compared to the males at ages of 4, 9 and 18 months. In the 5, 12 and 18th months, the mean corpuscular hemoglobin content $(\mathrm{MCH})$ values were higher in the female group. The mean corpuscular hemoglobin concentration (MCHC) values decreased in both genders at 18 months compared to 3 months. 

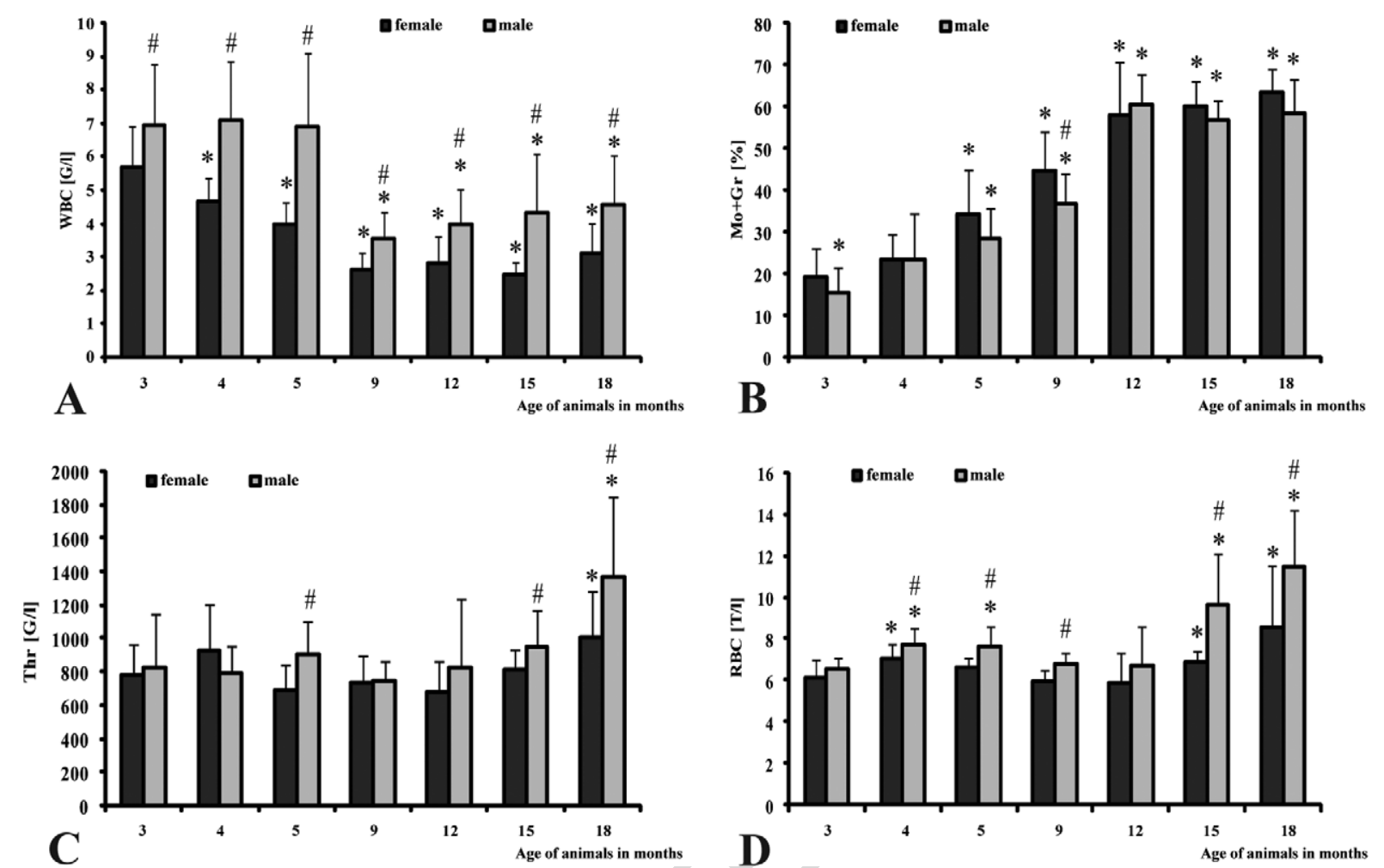

Fig. 2. Effects of age and gender on blood cell counts in rats. White blood cell (WBC) count (A), monocyte+granulocyte \% (B), platelet (Thr) count (C), red blood cell (RBC) count (D) in coeval male and female Crl:WI rats at the ages of 3, 4, 5, 9, 12, 15 and 18 months. Data are means \pm S.D., ${ }^{*} p<0.05$ vs. 3 -month old, ${ }^{\#} p<0.05$ vs. female.

\subsection{Red blood cell aggregation}

Figure 3 shows the changes in erythrocyte aggregation values. From 4 months onwards, M $5 \mathrm{~s}$ and M $10 \mathrm{~s}$ values for male rats were higher than female rats. Values for M1 $5 \mathrm{~s}$ and M1 $10 \mathrm{~s}$ were also higher for males at most times between 4-12 months. The changes with age were irregular, but vales tended to be higher at age $4-5$ months.

\subsection{Red blood cell deformability, membrane stability and osmotic responses}

Figure 4 shows the changes in elongation indices determined by the ektacytometer. The elongation at 3Pa shear stress was significantly higher for females than males. From the age of 9 months, this index was lower than at 3 months. The $\mathrm{EI}_{\max }$ also tended to be higher for the females and was significantly different compared to male values at the ages of 5, 9 and 12 months. EImax also tended to decrease with age. The $\mathrm{SS}_{1 / 2}$ values increased from 9 months until the end of the follow up period, and tended to be higher in males. The $\mathrm{EI}_{\mathrm{max}} / \mathrm{SS}_{1 / 2}$ was significantly higher in females from age 3 month to 9 month. Between the 12th and 18th month $\mathrm{EI}_{\max } / \mathrm{SS}_{1 / 2}$ values were decreased compared to 3 months both in male and female groups.

Figure 5 and Table 3 show values for osmoscan parameters. Maximal elongation (EI max, at osmolality close to the isotonic level) or minimal elongation (EI min, at low osmolality) did not vary consistently 


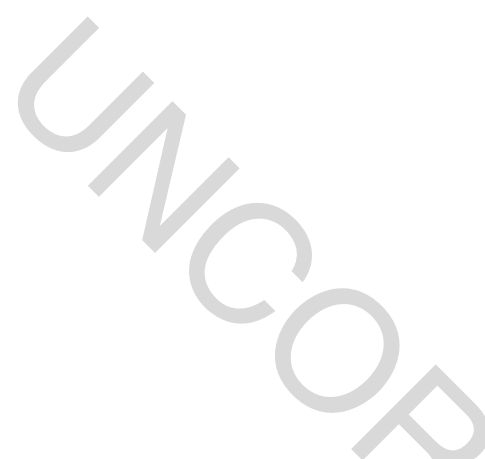

Table 2

Hematological values for male and female rats. Samples were obtained from coeval Crl:WI male and females rats at 3, 4, 5, 9, 12, 15 and 18 months of age

\begin{tabular}{lllcccccc}
\hline & & \multicolumn{5}{c}{ Follow-up period (age of the animals) } \\
\cline { 3 - 8 } & & \multicolumn{1}{c}{ 3-month } & 4-month & 5-month & 9-month & 12-month & 15-month \\
\hline Hgb [g/dl] & male & $12.84 \pm 0.74^{\#}$ & $13.05 \pm 0.72^{\#}$ & $12.6 \pm 0.8^{\#}$ & $12.02 \pm 0.38^{* \#}$ & $12.19 \pm 1.49$ & $14.9 \pm 3.72^{* \#}$ & $14.09 \pm 1.98$ \\
& female & $12.41 \pm 0.58$ & $12.09 \pm 1.03$ & $11.97 \pm 0.78^{*}$ & $10.82 \pm 0.32^{*}$ & $11.84 \pm 1.7$ & $11.42 \pm 0.42^{*}$ & $13.21 \pm 4.13^{*}$ \\
Hct [\%] & male & $45.47 \pm 4.13$ & $46.69 \pm 6.04$ & $47.85 \pm 6.93^{\#}$ & $39.87 \pm 5.85^{* \#}$ & $39.64 \pm 10.82$ & $56.01 \pm 14.62^{* \#}$ & $65.64 \pm 14.77^{*}$ \\
& female & $41.57 \pm 6.93$ & $46.21 \pm 5.98^{*}$ & $40.95 \pm 3.58$ & $36.6 \pm 4.45^{*}$ & $36.29 \pm 8.41^{*}$ & $43.92 \pm 1.6$ & $52.89 \pm 16.87^{*}$ \\
MCV [fl] & male & $69.64 \pm 5.9$ & $60.28 \pm 3.13^{* \#}$ & $62.82 \pm 3.88^{*}$ & $59.65 \pm 3.65^{* \#}$ & $59.22 \pm 2.23^{*}$ & $57.93 \pm 2.63^{*}$ & $57.5 \pm 1.46^{* \#}$ \\
& female & $68.31 \pm 3.83$ & $65.79 \pm 3.16^{*}$ & $61.69 \pm 3.44^{*}$ & $61.17 \pm 2.05^{*}$ & $62.11 \pm 4.82^{*}$ & $63.88 \pm 4.48^{*}$ & $64.98 \pm 11.24^{*}$ \\
MCH [pg] & male & $19.68 \pm 1.41$ & $16.98 \pm 1.15^{*}$ & $16.71 \pm 1.53^{* \#}$ & $17.88 \pm 1.4^{*}$ & $19.53 \pm 5.52^{* \#}$ & $15.68 \pm 2.38^{*}$ & $12.88 \pm 2.35^{* \#}$ \\
& female & $20.78 \pm 2.76$ & $17.3 \pm 0.74^{*}$ & $18.07 \pm 1.15^{*}$ & $18.26 \pm 1.71^{*}$ & $20.77 \pm 3.51$ & $16.63 \pm 1.31^{*}$ & $16.24 \pm 2.9^{*}$ \\
MCHC [g/dl] & male & $28.44 \pm 2.95$ & $28.25 \pm 2.69^{*}$ & $26.73 \pm 3.08^{* \#}$ & $30.09 \pm 2.9$ & $32.87 \pm 9.19$ & $27.04 \pm 3.98$ & $22.31 \pm 3.61^{* \#}$ \\
& female & $30.46 \pm 4.05$ & $26.37 \pm 1.89^{*}$ & $29.32 \pm 1.49$ & $29.94 \pm 3.5$ & $33.47 \pm 5.09$ & $26.06 \pm 1.67^{*}$ & $25.19 \pm 3.93^{*}$ \\
\hline
\end{tabular}

Data are mean \pm S.D. ${ }^{*} p<0.05$ vs. 3-month old, ${ }^{\#} p<0.05$ vs. female. 

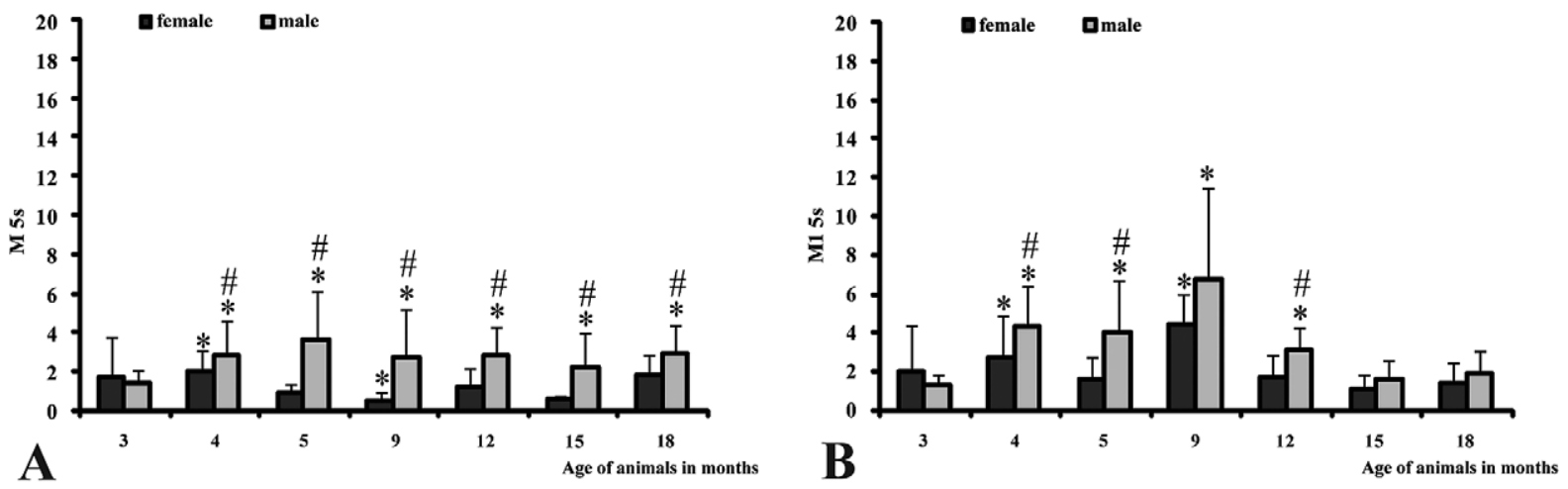
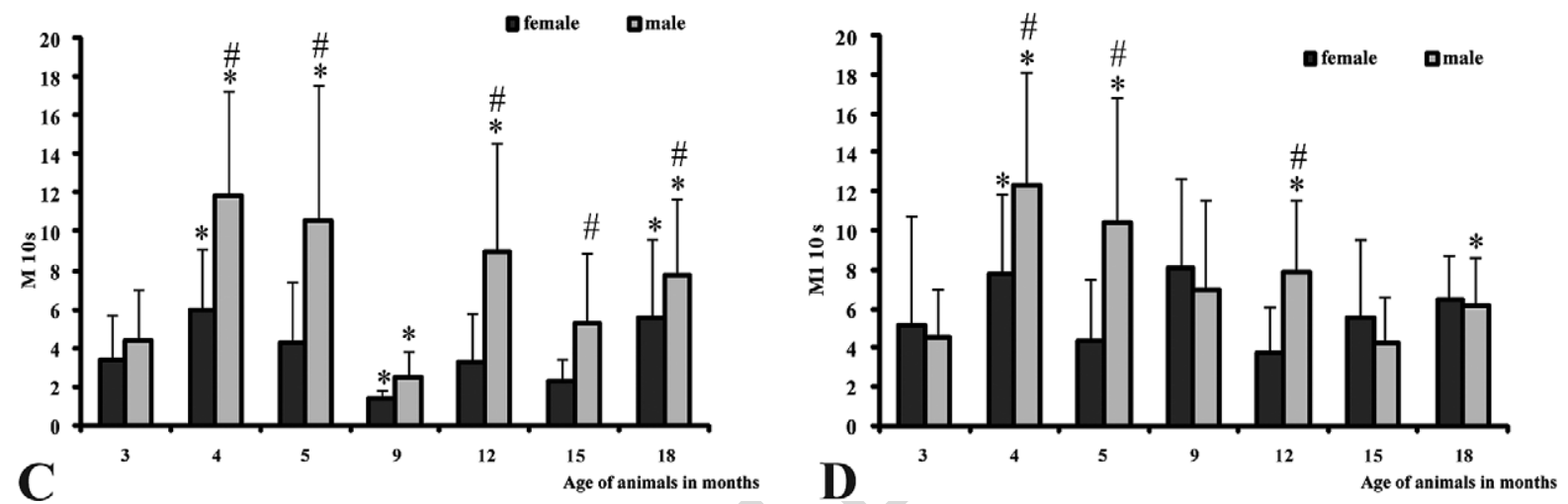

Fig. 3. Effects of age and gender on red cell aggregation in rats. Aggregation indices M $5 \mathrm{~s}$ (A), M1 $5 \mathrm{~s}$ (B), M10 s (C) and M1 $10 \mathrm{~s}(\mathrm{D})$ in coeval male and female Crl:WI rats at the ages of 3, 4, 5, 9, 12, 15 and 18 months. Data are means \pm S.D., ${ }^{*} p<0.05$ vs. 3 -month old, ${ }^{\#} p<0.05$ vs. female.

with age or between genders (Figure 5(A), (C)). EI max showed decreased values between ages of 9-12 months, while EI min values increased significantly by the end of the observation period in both genders. The $\mathrm{O}$ min and $\mathrm{O}$ EImax values in males were lower than in females in every month, with the differences at 4, 5, 9 and 15 months statistically significant (Figure 5(B), (D)). EI hyper values reflected the changes in EImax, as they calculated from the latter parameter (Table 3). O hyper values did not show consistent variation with age or between genders over the first 9 months, but then decreased so that at the end of the observation period $\mathrm{O}$ hyper was significantly decreased compared to the base (3-month) data. In males, AUC was lowered at 9 and 12 months, but otherwise, no clear trends were evident. The $\Delta E I$ and $\Delta O$ and their ratio may provide additional information about the hypo-osmolar part of the osmoscan curve (between EI min and EI max, O min and O EI max). Cells are swelling in this region until their rupture. We found significant decrease in $\Delta \mathrm{EI}$ in the blood samples of 9- and 12-month males and 12-month females. $\Delta \mathrm{O}$ values were higher in females than males at most ages. After increasing between ages of $5-12$, values slightly decreased in samples of 15 - or 18 -month male animals. The ratio of $\Delta E I / \Delta O$ values was almost unchanged throughout.

The major changes in hematological and rheological parameters are summarised in Table 4. 

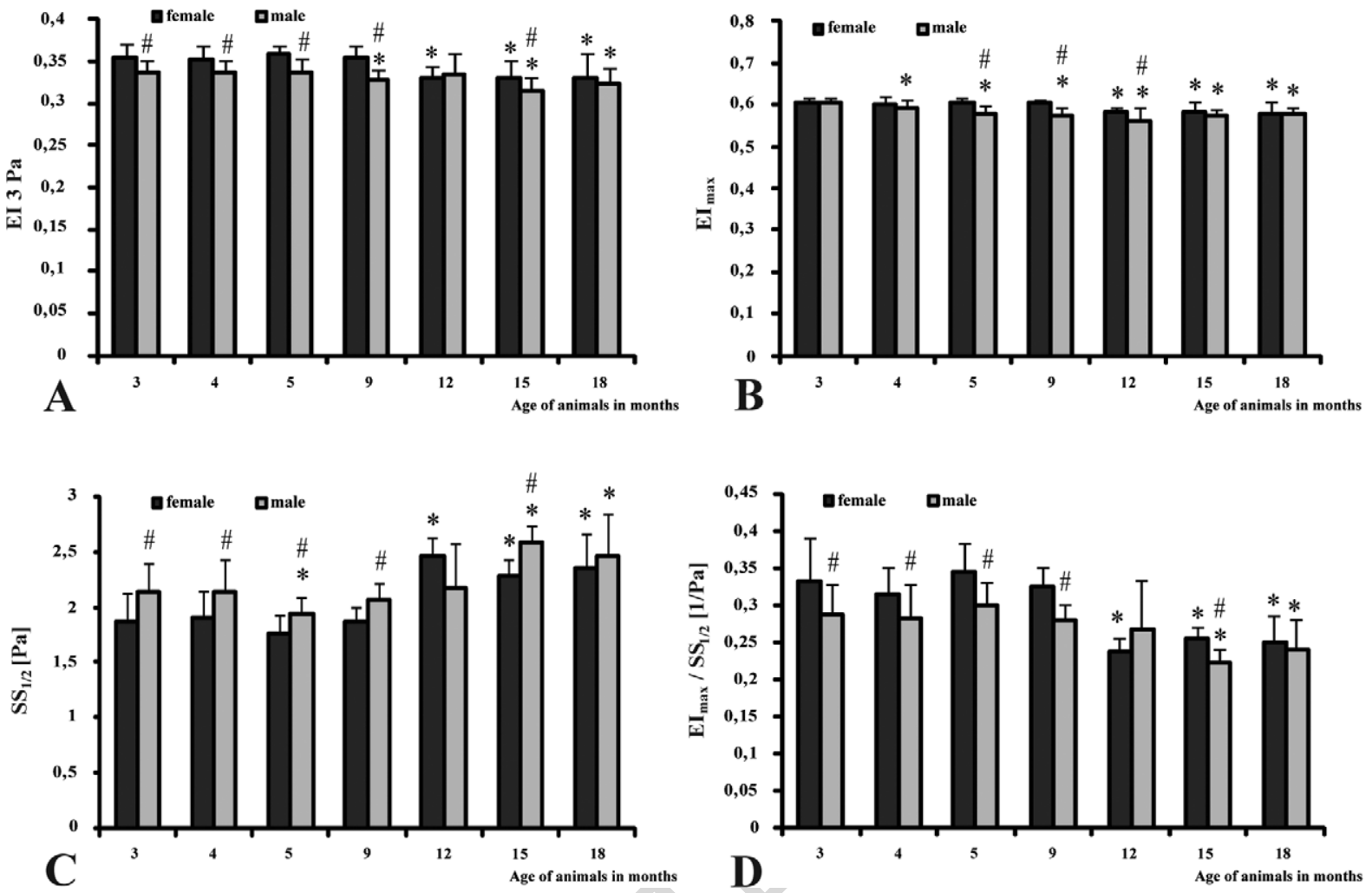

Fig. 4. Effects of age and gender on red cell elongation indices in rats. EI values at $3 \mathrm{~Pa}(\mathrm{~A})$, maximal elongation index $\mathrm{EI}_{\max }(\mathrm{B})$, shear stress values at half $\mathrm{EI}_{\max }\left(\mathrm{SS}_{1 / 2}\right)(\mathrm{C})$, the ratio of $\mathrm{EI}_{\max } / \mathrm{SS}_{1 / 2}(\mathrm{D})$ of coeval male and female Crl:WI rats at the ages of $3,4,5,9,12,15$ and 18 months. Data are means \pm S.D., ${ }^{*} p<0.05$ vs. 3 -month old, ${ }^{\#} p<0.05$ vs. female.

\section{Discussion}

Red blood cell deformability and aggregation play important roles in determining microcirculatory perfusion, and these factors may alter significantly in various pathophysiological processes [28,31-34]. Resistance of red blood cells to mechanical stress and to osmotic changes affects their deformability, aggregability, as well as their life-span [18,30,35]. Osmotic gradient ektacytometry (measuring elongation index as a function of osmolality at a constant shear stress) is a sensitive method to analyze red blood cell deformability, investigating the optimal osmolality range for the cells in normal or pathophysiological cellular and micro-environmental conditions $[18,30]$. Thus, investigating microrheological factors is important to understand blood circulation and research often needs experimental models, such as rats. Experimental protocols, for instance in surgical studies, often need follow-up periods, so that age- and gender-related effects on parameters have to be considered.

According to the literature, red blood cell deformability and aggregation values vary between different species (e.g. [36,37]). However, less is known about the gender and age-related differences. Previously, we studied red blood cell deformability and aggregation in rats and dogs, and found that female animals had higher red blood cell deformability index values in rats, while in dogs the male animals possessed higher elongation index [26]. In the case of red blood cell aggregation, there is a different trend in humans. According to numerous articles, human males have increased red blood cell aggregation and lower deformability scores compared to females $[7,9,10]$. 

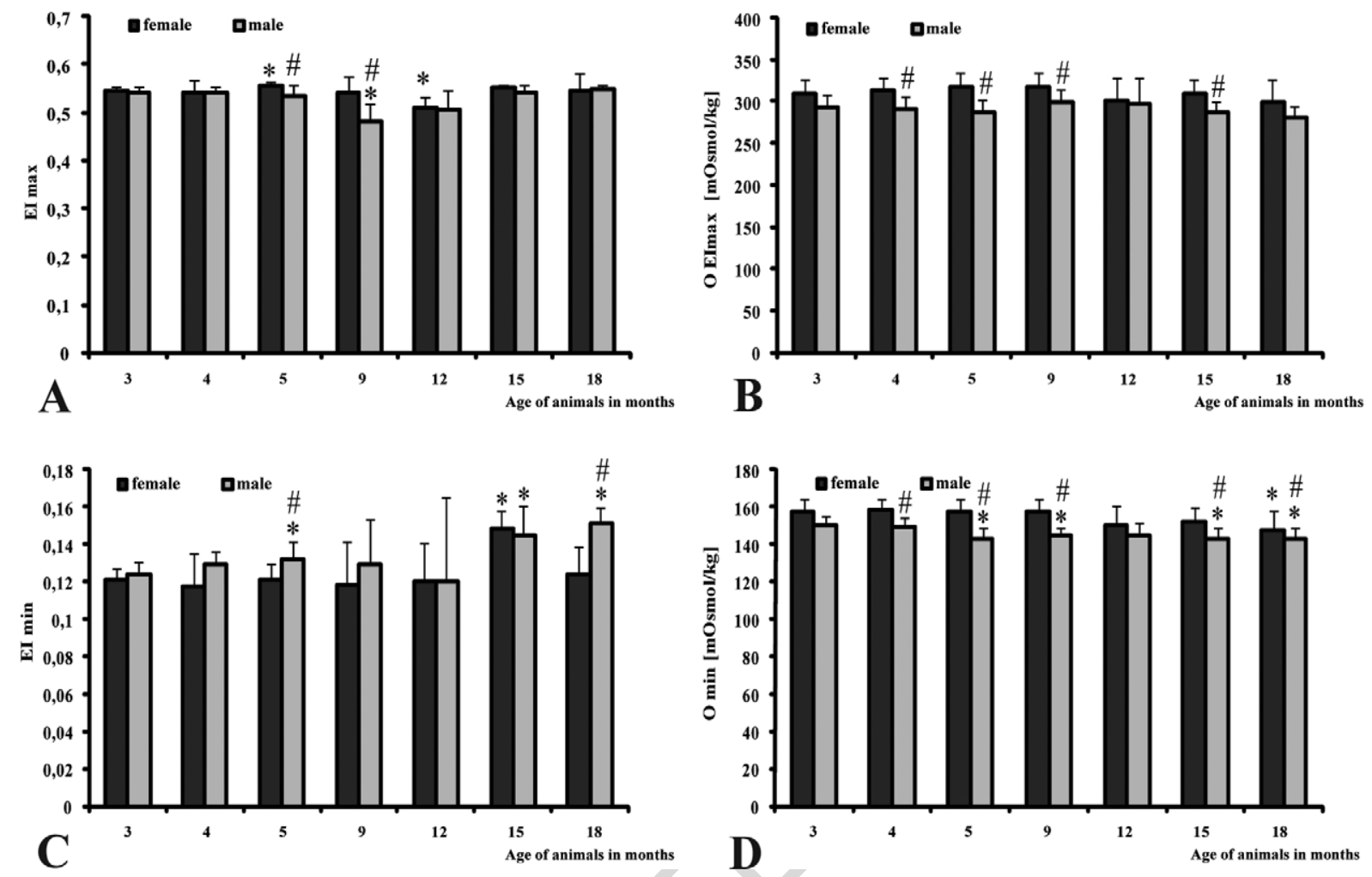

Fig. 5. Effects of age and gender on red cell osmoscan parameters in rats. Maximal EI (EI max) (A), osmolality of the maximal elongation index (O EI max) (B), minimal elongation index (EI min) (C), and osmolality of the minimal elongation index (O min) (D) measured by osmotic gradient ektacytometry (osmoscan) in coeval male and female Crl:WI rats at the ages of 3 , $4,5,9,12,15$ and 18 months. Data are means \pm S.D., ${ }^{*} p<0.05$ vs. 3 -month old, ${ }^{\#} p<0.05$ vs. female.

Red blood cell deformability is determined by intracellular viscosity, membrane viscosity and elasticity, surface area to cell volume ratio, and cell morphology. Red blood cell aggregation depends on cellular (cell morphology, deformability, properties of the cell surface glycocalyx) and plasmatic (fibrinogen and other protein levels) factors, besides the shear forces [28,31-34,38]. In addition to these factors, hormonal and metabolic aspects may also affect blood rheology [39].

Several studies have shown that hemorheological factors are significantly affected by aging $[21,24,40]$. The majority of the studies have reported increased plasma and whole blood viscosity [23], increased red blood cell aggregation and impaired red cell deformability in older age [6,11]. However, the agerelated hemorheological results are controversial. Some authors found either no correlation $[5,8,41]$ or concluded that not age itself, but certain risk factors are responsible for the alterations, involving obesity [42], hypertension [43], smoking [44] or medications [45]. The discrepancy may not only arise from the health status of donors, but also from use of different methods for the measurements, and differences in the gender and the age categories of the donors. Kameneva et al. demonstrated a statistically significant difference in the values for hemorheological parameters for male versus female. Men had higher hematocrit, blood viscosity, red blood cell aggregability and red blood cell rigidity, as well as lower deformability [6,7]. Based on experimental and clinical data, Simmonds et al. reviewed the altered blood rheology in aging and its related mechanisms, which included increased oxidative stress and the pro-inflammatory condition of aged individuals [13]. 


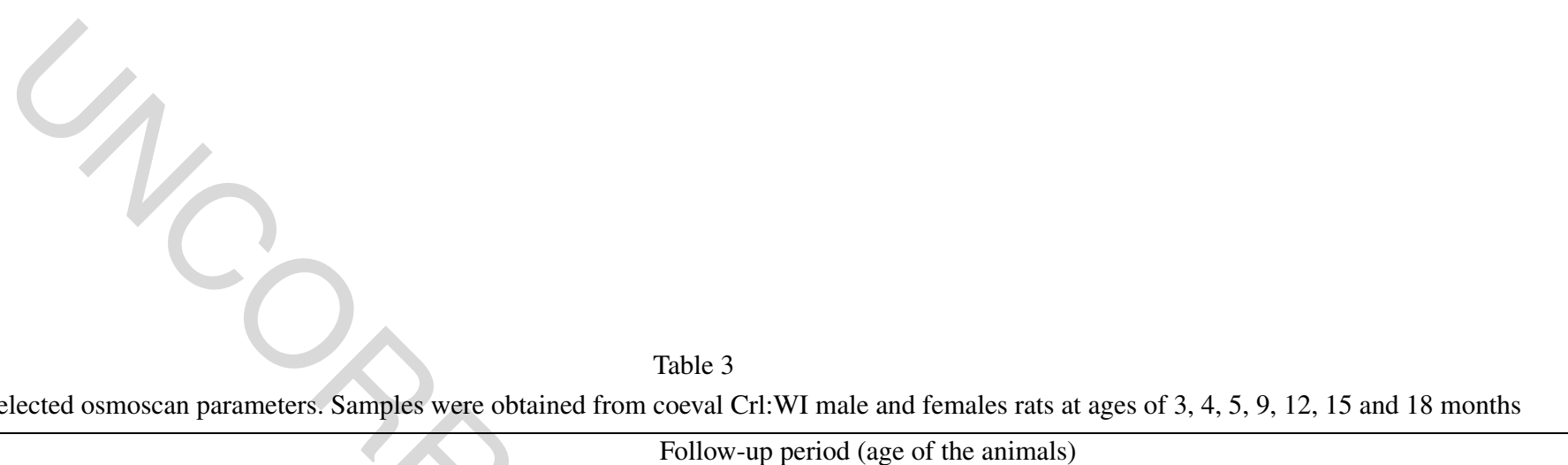

\begin{tabular}{|c|c|c|c|c|c|c|c|c|}
\hline & & & & & & & \\
\hline & & 3-month & 4-month & 5-month & 9-month & 12-month & 15-month & 18-month \\
\hline \multirow[t]{2}{*}{ EI hyper } & male & $0.27 \pm 0.01$ & $0.27 \pm 0.01$ & $0.27 \pm 0.01^{\#}$ & $0.24 \pm 0.02^{* \#}$ & $0.25 \pm 0.02$ & $0.27 \pm 0.01$ & $0.27 \pm 0.01$ \\
\hline & female & $0.27 \pm 0.01$ & $0.27 \pm 0.01$ & $0.28 \pm 0.01^{*}$ & $0.27 \pm 0.02$ & $0.26 \pm 0.01^{*}$ & $0.28 \pm 0.00$ & $0.27 \pm 0.02$ \\
\hline \multirow[t]{2}{*}{ O hyper $[\mathrm{mOsm} / \mathrm{kg}]$} & male & $453.4 \pm 14.63^{\#}$ & $446.1 \pm 8.67^{\#}$ & $447.7 \pm 9.84^{\#}$ & $471.33 \pm 10.32^{* \#}$ & $439.5 \pm 11.74^{*}$ & $422.38 \pm 6.37^{* \#}$ & $425.86 \pm 9.19^{*}$ \\
\hline & female & $466.2 \pm 10.23$ & $461.7 \pm 8.83$ & $458.7 \pm 7.24$ & $460.78 \pm 7.9$ & $431 \pm 9^{*}$ & $436.38 \pm 7.82^{*}$ & $425.63 \pm 8.65^{*}$ \\
\hline \multirow[t]{2}{*}{ Area } & male & $149.09 \pm 6.29$ & $146.19 \pm 5.1$ & $148.13 \pm 8.12$ & $128.19 \pm 13.89^{* \#}$ & $134.29 \pm 17.32^{*}$ & $143.14 \pm 5.83$ & $148.8 \pm 3.3$ \\
\hline & female & $148.19 \pm 4.89$ & $144.61 \pm 10.25$ & $153.85 \pm 4.18^{*}$ & $145.36 \pm 12.2$ & $131.46 \pm 10.46^{*}$ & $146.53 \pm 4.26$ & $145.26 \pm 10.74$ \\
\hline \multirow[t]{2}{*}{$\Delta \mathrm{EI}$} & male & $0.42 \pm 0.02$ & $0.41 \pm 0.01$ & $0.4 \pm 0.03^{\#}$ & $0.35 \pm 0.04^{* \#}$ & $0.38 \pm 0.02^{*}$ & $0.4 \pm 0.03$ & $0.4 \pm 0.01^{* \#}$ \\
\hline & female & $0.42 \pm 0.01$ & $0.42 \pm 0.02$ & $0.44 \pm 0.02$ & $0.42 \pm 0.04$ & $0.39 \pm 0.02^{*}$ & $0.4 \pm 0.02^{*}$ & $0.42 \pm 0.05$ \\
\hline \multirow[t]{2}{*}{$\Delta \mathrm{O}$} & male & $143.1 \pm 11.32$ & $142.1 \pm 12.48^{\#}$ & ${ }^{\#} 145.4 \pm 11.44^{\#}$ & $155.11 \pm 15.85$ & $152.25 \pm 27.85$ & $144.38 \pm 8.31^{\#}$ & $138.29 \pm 8.08$ \\
\hline & female & $152.1 \pm 12.73$ & $154.9 \pm 13.48$ & $158.7 \pm 13.04$ & $159.33 \pm 13.23$ & $151.78 \pm 17.93$ & $156.63 \pm 12.35$ & $152.63 \pm 15.86$ \\
\hline \multirow[t]{2}{*}{$\Delta \mathrm{EI} / \Delta \mathrm{O}$} & male & $0.003 \pm 0.0003$ & $0.003 \pm 0.0002$ & $20.003 \pm 0.0002$ & $20.002 \pm 0.0003^{* \#}$ & $0.003 \pm 0.0004^{*}$ & $0.003 \pm 0.0002$ & $0.003 \pm 0.0002$ \\
\hline & female & $0.003 \pm 0.0002$ & $0.003 \pm 0.0003$ & $3 \quad 0.003 \pm 0.0002$ & $20.003 \pm 0.0002$ & $0.003 \pm 0.0002$ & $0.003 \pm 0.0003$ & $0.003 \pm 0.0003$ \\
\hline \multicolumn{9}{|c|}{ Data are mean \pm S.D. ${ }^{*} p<0.05$ vs. 3 -month old, ${ }^{\#} p<0.05$ vs. female. } \\
\hline
\end{tabular}


Table 4

Summary of the variations in hematological and hemorheological parameters with gender or age

\begin{tabular}{|c|c|c|}
\hline \multirow[t]{2}{*}{ Parameters } & \multicolumn{2}{|c|}{ Main effects of gender or age } \\
\hline & Gender differences & Effects of age \\
\hline $\begin{array}{l}\text { Hematological } \\
\text { variables }\end{array}$ & $\begin{array}{l}\text { WBC, RBC, Hct, Hgb values were higher in } \\
\text { males. }\end{array}$ & $\begin{array}{l}\text { Total WBC decreased after age 5-months while } \\
\text { Mo+Gr\% gradually increased. } \\
\text { Plt count rose at } 18 \text {-months, along with RBC } \\
\text { count, Hct and } \mathrm{Hgb} \text {. } \\
\text { MCV decreased with age. }\end{array}$ \\
\hline $\begin{array}{l}\text { Red blood cell } \\
\text { aggregation }\end{array}$ & $\begin{array}{l}\text { Aggregation greater in males than females except } \\
\text { at } 3 \text { months. }\end{array}$ & $\begin{array}{l}\text { Aggregation tended to increase in males over } 3 \text { to } \\
5 \text { months and then decrease. } \\
\text { No clear effect of age in females. }\end{array}$ \\
\hline $\begin{array}{l}\text { Red blood cell } \\
\text { deformability }\end{array}$ & $\begin{array}{l}\text { Elongation greater in females than males, and } \\
\mathrm{SS}_{1 / 2} \text { lower in females. } \\
\text { Indicates greater deformability (elongation under } \\
\text { shear) in females. }\end{array}$ & $\begin{array}{l}\text { Decreasing EI and increasing } \mathrm{SS}_{1 / 2} \text { with age in } \\
\text { both genders, most evident at }>12 \text { months. } \\
\text { Indicates reduction in deformability (elongation } \\
\text { under shear) with age. }\end{array}$ \\
\hline $\begin{array}{l}\text { Osmotic } \\
\text { gradient } \\
\text { deformability }\end{array}$ & $\mathrm{O}$ EImax and $\mathrm{O}$ min lower in males. & $\begin{array}{l}\text { EI min increased with age, more evident in males. } \\
\text { O min decreased with age. } \\
\text { O hyper decreased with age. }\end{array}$ \\
\hline
\end{tabular}

Hemorheological aspects of aging and gender in rats have not been completely revealed before. Thus, we aimed to clarify these issues. Table 4 summarizes the main gender and age-related effects on hematological and red blood cell micro-rheological properties. When evaluating these results, several influencing factors and limitation have to be taken into consideration, such as possible strain-specific differences, estrous cycle, and seasonal effects.

The stage of the estrous cycle of the rats was assessed by a simple method (used since 1922), investigating the vaginal smears under a light microscope [27]. The animals were kept in a conventional animal house, so the Lee-Boot effect (suppression or prolongation of the estrous cycle when the females are held together without males in the room) was excluded, but not the Whitten effect (pheromones of male animals induce the synchronization of the estrous cycle in adult females). The menstrual cycle can modify the hematological parameters such as red blood cell and total leukocyte count in primates [46]. Also the different phases of estrous cycle (diestrus versus all another phases) can change the hematological values such as hemoglobin, red blood cell count and eosinophils in beagle dogs [47]. Cetin et al. have investigated the effect of gender, pregnancy and season on blood parameters in Angora rabbits, finding significant effects of gender, physiological status and periods of year [48]. Female rats' estrous cycle is about 3-5 days long (polyestrus animals). Aging may have effects on the rats' cycle by either prolonging or shortening it. Therefore we cannot directly link our hemorheological results to the estrous cycle. We tested the cycle with vaginal smear technique, showing just a "cross-section" of the estorus cycle in the group. It is one of the limitations of our study.

The effect of season cannot be excluded; however, we could not provide evidence on this issue. At the beginning of the follow-up period, in March, all the rats were 3-month old. The highest increase in aggregation index values of males was observed around the 4th and 5th months (still in spring), that was followed by a decline. During the winter, this tendency reversed itself, again the male values were higher, and the female values were lower in comparison. In parallel, leukocyte count also decreased.

Another limitation is the relatively infrequent blood sampling. We did not perform blood sampling more frequently, due to the effects of blood-loss and the necessary recovery time [49]. Our main concern was the animals' well-being during the study period. Furthermore, as the majority of studies are conducted on 3-4 and rarely up to 6 month old rats, over this period we did not want to affect the animals 
more. Blood samplings were performed under short general anesthesia. We experienced that with aging the effect of anesthesia can be also altered, so we also wished to reduce the risk of losing the animals. Also due to the limited blood sampling volume, we could not investigate further parameters, such as fibrinogen concentration, routine blood chemistry, enzymes and hemostatic parameters.

It has been stated that "Most of the researchers used to relate human and rat age by simply correlating their life span, which is not acceptable, because, for a specific research work, one uses a particular developmental phase of rat-life. Thus one should consider different phases of their life to have an accurate correlation" [25]. Laboratory rats live about 2-3.5 years. Considering the whole life-span, about 26.7 human days is equal to 1 rat day, and about 13.8 rat days is correlated to 1 human year. However in 'puberty', adult age, reproductive senescence and post senescence periods, the correlations can be different $[25,50,51]$. We followed-up the animals up to their age of 18 months, which can be correlated to about 45 years in human. A 36-month old rat would be correlated to a 90-year man [25]. Thus we have investigated the hemorheological alterations until the equivalent of a middle-aged human. We plan further studies to extend the follow-up period, together with regular blood pressure monitoring.

\section{Conclusion}

Blood micro-rheological parameters showed age-related alterations as well as gender differences. The effect of estrous cycle could not be excluded for female rats. These data could be useful for studying further the mechanism underlying age and gender differences in hemorheological parameters in rats, and as reference values for studies of these variables.

\section{Acknowledgements}

The authors are grateful to the technical staff of the Department of Operative Techniques and Surgical Research, Faculty of Medicine, University of Debrecen.

The authors confirm that the study complies with the Ethical Guidelines for Publication in Biorheology as published by IOS Press: https://www.iospress.nl/journal/biorheology/.

\section{References}

[1] Antonov P, Antonova M, Nikolova N, Antonova N, Vlaskovska M, Kasakov L. Age dependent changes of arterial wall viscoelasticity. Clin Hemorheol Microcirc. 2008;39:63-8.

[2] Nanayakkara S, Marwick TH, Kaye DM. The ageing heart: The systemic and coronary circulation. Heart. 2018;104:3706. doi:10.1136/heartjnl-2017-312114.

[3] North BJ, Sinclair DA. The intersection between aging and cardiovascular disease. Circ Res. 2012;110(8):1097-108. doi:10.1161/CIRCRESAHA.111.246876.

[4] Xu X, Wang B, Ren C, Hu J, Greenberg DA, Chen T, Xie L, Jin K. Age-related impairment of vascular structure and functions. Aging Dis. 2017;8(5):590-610. doi:10.14336/ad.2017.0430.

[5] Jung F, Roggenkamp HG, Ringelstein EB, Leipnitz G, Schneider R, Kiesewetter H. Effect of sex, age, bodyweight, and smoking on plasma viscosity. Klin Wochenschr. 1986;64(20):1076-81. doi:10.1007/BF01757212.

[6] Kameneva MV, Garrett KO, Watach MJ, Borovetz HS. Red blood cell aging and risk of cardiovascular diseases. Clin Hemorheol Microcirc. 1998;18:67-74.

[7] Kameneva MV, Watach MJ, Borovetz HS. Gender difference in rheologic properties of blood and risk of cardiovascular diseases. Clin Hemorheol Microcirc. 1999;21(3-4):357-63.

[8] Coppola L, Caserta F, De Lucia D, Guastafierro S, Grassia A, Coppola A, et al. Blood viscosity and aging. Arch Gerontol Geriatr. 2000;31:35-42. 
[9] Baev VM. Effect of sex on rheological properties of blood in adults. Klin Lab Diagn. 2001;12:33-5

[10] Bogár L, Juricskay I, Késmárky G, Fehér G, Kenyeres P, Tóth K. Gender differences in hemorheological parameters of coronary artery disease patients. Clin Hemorheol Microcirc. 2006;35:99-103.

[11] Fehér G, Koltai K, Késmárky G, Szapary L, Juricskay I, Tóth K. Hemorheological parameters and aging. Clin Hemorheol Microcirc. 2006;35(1-2):89-98.

[12] Kovács A, Szikszai Z, Várady E, Imre S. Study on hemorheological parameters of oldest-old residents in the EastHungarian city. Debrecen Clin Hemorheol Microcirc. 2006;35(1-2):83-8.

[13] Simmonds MJ, Meiselman HJ, Baskurt OK. Blood rheology and aging. J Geriatr Cardiol. 2013;10:291-301. doi:10.3969/ j.issn.1671-5411.2013.03.010.

[14] Nash GB, Meiselman HJ. Red cell and ghost viscoelasticity. Effects of hemoglobin concentration and in vivo aging. Biophys J. 1983;43(1):63-73. doi:10.1016/S0006-3495(83)84324-0.

[15] Piomelli S, Seaman C. Mechanism of red blood cell aging: Relationship of cell density and cell age. Am J Hematol. 1993;42(1):46-52. doi:10.1002/ajh.2830420110.

[16] Huang YX, Wu ZJ, Mehrishi J, Huang BT, Chen XY, Zheng XJ, Liu WJ, Luo M. Human red blood cell aging: Correlative changes in surface charge and cell properties. J Cell Mol Med. 2011;15(12):2634-42. doi:10.1111/j.1582-4934.2011. 01310.x.

[17] Waugh RE, Narla M, Jackson CW, Mueller TJ, Suzuki T, Dale GL. Rheologic properties of senescent erythrocytes: Loss of surface area and volume with red blood cell age. Blood. 1992;79(5):1351-8.

[18] Hardeman MR, Goedhart PT, Shin S. Methods in hemorheology. In: Baskurt OK, Hardeman HR, Rampling MW, Meiselman HJ, editors. Handbook of hemorheology and hemodynamics. Amsterdam: IOS Press; 2007. p. 242-66.

[19] Baskurt OK, Boynard M, Cokelet GC, Connes P, Cooke BM, Forconi S, et al. New guidelines for hemorheological laboratory techniques. Clin Hemorheol Microcirc. 2009;42(2):75-97. doi:10.3233/CH-2009-1202.

[20] Baskurt OK, Neu B, Meiselman HJ. Measurement of red blood cell aggregation. In: Baskurt OK, Neu B, Meiselman HJ, editors. Red blood cell aggregation. Boca Raton, USA: CRC Press; 2011. p. 63-132.

[21] Ajmani RS, Rifkind JM. Hemorheological changes during human aging. Gerontology. 1998;44(2):111-20. doi:10.1159/ 000021993.

[22] Michalska-Malecka K, Slowinska L, Dorecka M, Romaniuk W. Correlations in some pathogenetic factors and values of hemorheological parameters in age-related macular degeneration. Clin Hemorheol Microcirc. 2008;39:209-16.

[23] Carallo C, Irace C, De Franceschi MS, Coppoletta F, Tiriolo R, Scicchitano C, et al. The effect of aging on blood and plasma viscosity. An 11.6 years follow-up study. Clin Hemorheol Microcirc. 2011;47(1):67-74. doi:10.3233/CH-20101367.

[24] Vayá A, Alis R, Romagnoli M, Pérez R, Bautista D, Alonso R, Laiz B. Rheological blood behavior is not only influenced by cardiovascular risk factors but also by aging itself. research into 927 healthy Spanish Mediterranean subjects. Clin Hemorheol Microcirc. 2013;54(3):287-96. doi:10.3233/CH-131734.

[25] Sengupta P. The laboratory rat: Relating its age with human's. Int J Prev Med. 2013;4(6):624-30.

[26] Németh N, Kiss F, Furka I, Mikó I. Gender differences of blood rheological parameters in laboratory animals. Clin Hemorheol Microcirc. 2010;45:263-72.

[27] Cora MC, Kooistra L, Travlos G. Vaginal cytology of the laboratory rat and mouse: Review and criteria for the staging of the estrous cycle using stained vaginal smears. Toxicol Pathol. 2015;43(6):776-93. doi:10.1177/0192623315570339.

[28] Schmid-Schönbein H, Malotta H, Striesow F. Erythrocyte aggregation: Causes, consequences and methods for assessment. Tijdschr NVKC. 1990;15:88-97.

[29] Baskurt OK, Hardeman MR, Uyuklu M, Ulker P, Cengiz M, Nemeth N, et al. Parameterization of red blood cell elongation index - shear stress curves obtained by ektacytometry. Scand J Clin Lab Invest. 2009;69(7):777-88. doi:10.3109/ 00365510903266069.

[30] Németh N, Kiss F, Miszti-Blasius K. Interpretation of osmotic gradient ektacytometry (osmoscan) data: A comparative study for methodological standards. Scand J Clin Lab Invest. 2015;75(3):213-22. doi:10.3109/00365513.2014.993695.

[31] Meiselman HJ. Morphological determinants of red cell deformability. Scand J Clin Lab Invest Suppl. 1981;156:27-34. doi: $10.3109 / 00365518109097426$.

[32] Stuart J. Erythrocyte rheology. J Clin Pathol. 1988;38:965-77. doi:10.1136/jcp.38.9.965.

[33] Stoltz JF, Singh M, Riha P, editors. In: Hemorheology in practice. Amsterdam, The Netherlands: IOS Press; 1999. p. 9-52.

[34] Neu B, Meiselman HJ. Red blood cell aggregation. In: Baskurt OK, Hardeman MR, Rampling MW, Meiselman HJ, editors. Handbook of hemorheology and hemodynamics. Amsterdam, The Netherlands: IOS Press; 2007. p. 114-36.

[35] Baskurt OK, Meiselman HJ. Red blood cell mechanical stability test. Clin Hemorheol Microcirc. 2013;55(1):55-62. doi:10.3233/CH-131689.

[36] Plasenzotti R, Stoiber B, Posch M, Windberger U. Red blood cell deformability and aggregation behaviour in different animal species. Clin Hemorheol Microcirc. 2004;31:105-11. 
[37] Windberger U, Baskurt OK. Comparative hemorheology. In: Baskurt OK, Hardeman HR, Rampling MW, Meiselman HJ, editors. Handbook of hemorheology and hemodynamics. Amsterdam: IOS Press; 2007. p. 267-85.

[38] Dormandy JA. Red blood cell deformability. Eur Neurol. 1983;22:181-4.

[39] Brun JF. Hormones, metabolism and body composition as major determinants of blood rheology: Potential pathophysiological meaning. Clin Hemorheol Microcirc. 2002;26(2):63-79.

[40] Coppola L, Guastafierro S, Sagristani M, Coppola A, Nasuti A, Ruggiero L, et al. Decreased hemoglobin levels are associated with higher plasma level of fibrinogen, irrespective of age. Am J Med Sci. 2007;333:154-60. doi:10.1097/ MAJ.0b013e3180312547.

[41] Konstantinova E, Tolstaya T, Prishchep S, Milutin A, Mironova E, Ivanova L. Plasma lipid levels, blood rheology, platelet aggregation, microcirculation state and oxygen transfer to tissues in young and middle-aged healthy people. Clin Hemorheol Microcirc. 2004;30(3-4):443-8.

[42] Jarnell WJ, Swwetnam PM, Rumley A, Lowe GD. Lifestyle and hemostatic risk factors for ischemic heart disease: The caerphilly study. Arterioscler Thromb Vasc Biol. 2000;20:271-9. doi:10.1161/01.ATV.20.1.271.

[43] Tóth K, Késmárky G, Vékási J, Nemes J, Czopf L, Kapronczay P, et al. Hemorheological and hemodynamic parameters in patients with essential hypertension and their modification by alpha-1 inhibitor drug treatment. Clin Hemorheol Microcirc. 1999;21(3-4):209-16.

[44] Ernst E, Koenig W, Matrai A, Filipiak B, Stieber J. Blood rheology in healthy cigarette smokers: Results from the MONICA-project. Arterioscler. 1988;8:385-8. doi:10.1161/01.ATV.8.4.385.

[45] Gibbs CR, Blann AD, Watson RD, Lip GYH. Abnormalities of hemorheological, endothelial, and platelet function in patients with chronic heart failure in sinus rhytmn. Effects of angiotensin-converting enzyme inhibitor and beta-blocker therapy. Circulation. 2001;103:1746-51. doi:10.1161/01.CIR.103.13.1746.

[46] Harewood WJ, Gillin A, Hennessy A, Armitstead J, Horvath JS, Tiller DJ. The effects of the menstrual cycle, pregnancy and early lactation on haematology and plasma biochemistry in the baboon (Papio hamadryas). J Med Primatol. 2000;29(6):415-20. doi:10.1111/j.1600-0684.2000.290606.x.

[47] Willson CJ, Chandra SA, Kimbrough CL, Jordan HL. Effect of estrus cycle phase on clinical pathology values in beagle dogs. Vet Clin Pathol. 2012;41(1):71-6. doi:10.1111/j.1939-165X.2011.00392.x.

[48] Cetin N, Bekyürek T, Cetin E. Effect of sex, pregnancy and season on some haematological and biochemical blood values in angora rabbits. Scand J Lab Anim Sci. 2009;36(2):155-62.

[49] Animal Care and Use Policies and Guidelines. Veterinary Recommendations for Multiple Blood Draws - Volumes and Frequency [homepage on the Internet]. Johns Hopkins University Available from: http://web.jhu.edu/animalcare/policies/ multiple-blood-draws.html.

[50] Quinn R. Comparing rat's to human's age: How old is my rat in people years? Nutrition. 2005;21(6):775-7. doi:10.1016/ j.nut.2005.04.002.

[51] Sengupta P. A scientific review of age determination for a laboratory rat: How old is it in comparison with human age? Biomed Int. 2012;2:81-9. 